\title{
FAKTOR-FAKTOR YANG MEMPENGARUHI NILAI PERUSAHAAN PADA PERUSAHAAN YANG TERDAFTAR DI BURSA EFEK MALAYSIA DAN BURSA EFEK INDONESIA
}

\author{
Sri Hermuningsih \\ Fakultas Ekonomi, Universitas Sarjanawiyata Tamansiswa \\ e-mail: hermun_feust@yahoo.com \\ Dewi Kusuma Wardani \\ Fakultas Ekonomi, Universitas Sarjanawiyata Tamansiswa \\ e-mail:d3wi_kusuma@yahoo.co.id
}

\begin{abstract}
The objective of this study was proving the influences of insider ownership, debt policy and dividend policy to firm value at companies listed in Malaysia Stock Exchange and Indonesia Stock Exchange during 2003 to 2008. This study used multistage regression to reach the objective. The results indicate that in Malaysia, insider ownership and debt policy have an effect to dividend policy but have not a significant effect to firm value and in Indonesia, insider ownership and debt policy have not an effect to dividend policy and dividen policy also not have an effect to company value. Beside that the Malaysian and Indonesia investors do not use a dividend policy as a positif signal because many firms give dividend although they have not profit.
\end{abstract}

Keywords:insider ownership, debt policy, dividend policy, firm value

\section{PENDAHULUAN}

Perusahaan didirikan dan dijalankan untuk mencapai tujuan kesejahteraan pemilik, yang ditunjukkan oleh harga saham. Harga pasar saham juga menunjukkan nilai perusahaan. Bila harga saham meningkat berarti nilai perusahaan meningkat dan kesejahteraan pemilik meningkat. Para pemilik modal (sebagai principal) memberi kepercayaan kepada para profesional (manajerial) atau insider untuk mencapai tujuan tersebut (Harjito, 2006). Pemberian kepercayaan oleh pemilik modal kepada insider merupakan pemisahan fungsi antara fungsi pengambilan keputusan dan fungsi risk bearing (Jansen and Meckling, 1976). Pemodal berkepentingan untuk memperoleh keuntungan dari dananya yang diinvestasikan, sedangkan insider memiliki hak atas gaji dan kompensasi lainnya karena menjalankan amanat termasuk mengambil keputusan-keputusan bisnis yang diharapkan terbaik bagi pemilik modal. Namun demikian pihak insider sering bekerja bukan untuk memaksimumkan nilai perusahaan, tapi justru mengurusi atau berkutat pada peningkatan kesejahteraan insider sendiri. Namun dengan adanya insider ownership maka kecenderungan ini akan berubah karena insider merangkap sebagai pemilik modal. Dengan adanya insider ownership maka dimungkinkan insider juga ingin memaksimumkan nilai perusahaan dengan menggunakan wewenangnya dalam menentukan berbagai kebijakan perusahaan, seperti kebijakan dividen dan kebijakan hutang. Kebijakan dividen, insider ownership dan kebijakan hutang itu sendiri dapat 
saling mempengaruhi (interdependensi) secara simultan. Jensen dan Meckling (1976) menjelaskan bahwa proporsi ekuitas yang dikontrol oleh para insider dapat mempengaruhi kebijakan-kebijakan perusahaan. Leland dan Pyle (1977) dan Ross (1977) menyajikan hipotesis bahwa insider ownership dan kebijakan finansial dapat membantu menyelesaikan asimetri informasional antara manajer dengan investor eksternal.

Menurut La Porta et al. (1998) perbedaan dalam perlindungan hukum investor dapat menjelaskan variasi tentang bagaimana perusahaan yang dibiayai dan dimiliki. La Porta et al. menemukan sebuah hubungan positif antara nilai perusahaan dan perlindungan investor dalam sisi hukum, karena dalam kasus ini pengambil-alihan kekayaan minoritas dihindari. Indonesia adalah negara yang menggunakan civil law, dimana minoritas dan kreditor tidak dilindungi serta dividen wajib yang ditetapkan. Tidak hanya aturan-aturan hukum yang lemah melidungi, tetapi juga kualitas penegakannya juga lemah sehingga manajer dapat melakukan penyalahgunaan pentingnya mereka dalam mengambil alih perusahaan oleh investor (La Porta et al., 1998). Akibatnya, kontrol terkonsentrasi diperlukan untuk menghindari pengambilalihan serta untuk meningkatkan nilai perusahaan. Sedangkan Malaysia merupakan negara yang menggunakan common law, dimana merupakan undang-undang yang paling kuat melindungi investor dan kreditur. Mekanisme eksternal penting untuk mengendalikan manajer dan insider ownership. Karena jumlah insider ownership dibatasi maka konsentrasi kepemilikan tidak mungkin dapat dilakukan. Sehingga insider ownership tidak mungkin akan meningkatkan nilai perusahaan karena kepentingan antara pemilik dan agen diselaraskan karena kontrol pasar dan tindakan disiplin manajer. Sebagai hasilnya, di negara pengguna common law ini struktur kepemilikan perusahaan ditandai oleh beragam investor minoritas yang biasanya mengontrak manajer profesional untuk mengendalikan perusahaan (Lisboa dan Esperanca, 2006). Karena Indonesia dan Malaysia menggunakan jenis undang-undang perlindungan investor yang berbeda maka pengaruh insider ownership yang menyebabkan konflik keagenan oleh manajer akan berbeda dan nilai perusahaan pun akan berbeda. Indonesia yang menerapkan aturan hukum yang lebih lemah daripada Malaysia akan mendapati nilai perusahaan akibat konflik keagenan yang lebih besar daripada Malaysia. Oleh sebab itu penelitian ini ingin melihat faktor-faktor yang mempengaruhi nilai perusahaan pada perusahaan yang terdaftar di Bursa Efek Indonesia dan Bursa Efek Malaysia.

\section{KAJIAN TEORI \\ Nilai Perusahaan}

Nilai perusahaan merupakan persepsi investor terhadap perusahaan, yang sering dikaitkan harga saham. Harga saham yang tinggi membuat nilai perusahaan juga tinggi.Harga saham merupakan harga yang terjadi pada saat saham diperdagangkan di pasar (Fakhrudin and Hadianto, 2001). Nilai perusahaan lazim diindikasikan dengan price to book value. Price to book value yang tinggi akan membuat pasar percaya atas prospek perusahaan ke depan. Hal iini juga menjadi keinginan para pemilik perusahaan, sebab nila perusahaan yang tinggi mengindikasikan kemakmuran pemegang saham juga tinggi (Soliha and Taswan, 2002).Dalam realitasnya tidak semua perusahaan menginginkan harga saham tinggi (mahal), karena takut tidak laku dijual atau tidak menarik investor untuk membelinya. Hal ini bisa dibuktikan dengan adanya perusahaan-perusahaan yang go public di Bursa Efek Indonesia yang melakukan stock split ( memecah saham). Itulah sebabnya harga saham harus dapat di buat seoptimal 
mungkin. Artinya harga saham tidak boleh terlalu tinggi atau terlalu rendah. Harga saham yang terlalu murah dapat berdampak buruk pada citra perusahaan dimata investor. Terdapat beberapa faktor yang mempengaruhi nilai perusahaan antara lain insider ownership, kebijakan hutang, serta kebijakan dividen.

\section{Insider ownership}

Insider ownership merupakan persentase saham yang dimiliki oleh insider, seperti manajer atau direktur. Menurut penelitian Easterbrook (1984) dan Jensen (1986) insider ownership berpengaruh pada kebijakan dividen. Dalam penelitian Sartono (2006 dalam Harjito 2007), kenaikan tingkat insider ownership mengakibatkan penurunan kebijakan pembayaran deviden karena insider akan cenderung mengurangi pembayaran dividen untuk memperbesar atau memperluas usaha.

\section{Kebijakan Hutang}

Hutang merupakan salah satu sumber pembiayaan eksternal yang digunakan oleh perusahaan untuk membiayai kebutuhan dananya. Dalam pengambilan keputusan akan penggunaan hutang ini harus mempertimbangkan besarnya biaya tetap yang muncul dari hutang berupa bunga yang akan menyebabkan semakin meningkatnya leverage keuangan dan semakin tidak pastinya tingkat pengembalian bagi para pemegang saham biasa. Tingkat penggunaan hutang dari suatu perusahaan dapat ditunjukkan oleh salah satunya menggunakan rasio hutang terhadap ekuitas (DER), yaitu rasio jumlah hutang terhadap jumlah modal sendiri.

\section{Kebijakan Dividen}

Dividen adalah bagian dari laba bersih yang dibagikan kepada pemegang saham. Kebijakan dividen adalah kebijakan yang dikaitkan dengan penentuan apakah laba yang diperoleh perusahaan akan dibagikan kepada para pemegang saham sebagai dividen atau akan ditahan dalam bentuk laba ditahan. Kebijakan terhadap pembayaran dividen merupakan keputusan yang sangat penting dalam suatu perusahaan. Kebijakan ini akan melibatkan dua pihak yang mempunyai kepentingan yang berbeda, yaitu pihak pertama para pemegang saham, dan pihak kedua perusahaan itu sendiri.

Kebijakan Dividen bisa dikaitkan dengan nilai perusahaan. Hipotesis kebijakan dividen dan bird in the hand theory menurut Gordon (1962) dalam Brigham dan Gapenski, 1996: 438) yang menyatakan bahwa dividen yang tinggi dapat meningkatkan nilai perusahaan. Bird in the hand theory menyatakan bahwa pemegang saham lebih menyukai dividen yang tinggi karena memiliki kepastian yang tinggi dibandingkan capital gain.

\section{Kerangka Pemikiran}

Dalam penelitian ini meneliti tentang bagaimana pengaruh kebijakan dividen dan kebijakan hutang terhadap nilai perusahaan pada perusahaan yang terdaftar di Bursa Efek Indonesia dan Bursa Efek Malaysia diskemakan pada kerangka pemikiran berikut ini:

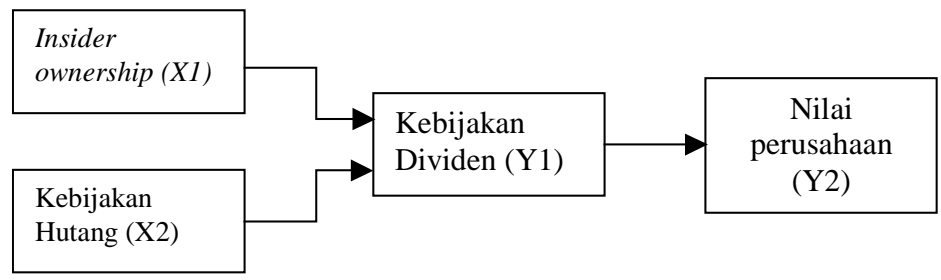

Gambar 1: Kerangka Penelitian 


\section{Hipotesis}

Insider ownership dan Kebijakan Dividen

Jensen, at al (1992) yang melakukan penelitian tentang hubungan antara insider ownership, kebijakan hutang dan kebijakan dividen dengan menggunakan analisa least square 3 tahap. Hasilnya mendukung pernyataan bahwa ownership, kebijakan hutang dan kebijakan dividen mempunyai hubungan yang interdependensi. Secara khusus insider ownership berpengaruh negatif terhadap kebijakan hutang dan dividen. Dengan demikian hipotesis yang dibangun dalam penelitian ini adalah bahwa insider ownership berhubungan negatif dengan kebijakan dividen.

H1: Insider ownership berpengaruh negatif terhadap kebijakan deviden.

\section{Kebijakan Hutang dan Kebijakan Dividen} Interdependensi antara kebijakan hutang dengan dividen dalam perspektif teori keagenan masih tergolong dalam lingkup penelitian behavioral (walaupun aspek kuantitatif keuangan lebih ditonjolkan) karena adanya dampak dari prilaku manajemen dan pemegang saham yang mempengaruhi keputusan keuangan perusahan. Prilaku principal-agent dalam perusahan membawa pengaruh adanya konflik kepentingan yang digerakkan oleh governance mechanism (Eisenhardt, 1989 dalam Harjito, 2006). Eisenhardt (1989) membagi teori keagenan kedalam dua aliran yaitu Positivist Agency Theory dan Principal-Agent Research. Penelitian yang akan dilakukan ini lebih mengarah kepada positivist agencytheory karena menguji hubungan keagenan antara manajemen (agent) dengan pemegang saham (principal). Hubungan antara hutang dengan dividen diuji oleh Masulis dan DeAngelo (1988) bahwa hutang dan dividen relevan bila terdapat pajak dan tidak terjadi ekuilibrium. Koch dan Shenoy (1999 dalam Harjito 2007) membuktikan bahwa terdapat inter- dependensi antara kebijakan hutang dengan dividen yang secara signifikan bersamasama mempengaruhi future cash flow. Hartono (2005) menemukan bahwa kebijakan dividen merupakan mekanisme untuk mempengaruhi kebijakan hutang. Jensen, Solberg dan Zorn (1992) menemukan bahwa manajemen akan melakukan trade-off antara pembayaran dividen dengan tagihan tetap dari hutang. Dividen yang tinggi bisa mencerminkan bahwa perusahan tidak mempunyai potencial opportunity investment, hal ini biasanya terjadi untuk perusahaan nongrowth sehingga hutang akan rendah (Gaver dan Gaver, 1993). Hubungan hutang dengan dividen adalah negatif, menurut bukti empiris diatas. Oleh karena itu hipotesis yang dapat dibangun adalah:

H2: Kebijakan hutang berpengaruh negatif terhadap kebijakan deviden

\section{Kebijakan Dividen dan Nilai Perusahaan}

Ada tiga kelompok yaitu MM (Modigliani dan Miller, 1958) berpendapat bahwa kebijakan dividen tidak relevan yang berarti tidak ada kebijakan dividen yang optimal karena dividen tidak mempengaruhi nilai perusahaan. Kelompok kedua adalah pendapat Gordon-Lintner yaitu dividen lebih kecil resikonya daripada capital gain, sehingga dividen setelah pajak dan menawarkan dividen yield yang lebih tinggi akan meminimumkan biaya modal. Kelompok ketiga adalah bahwa karena dividen cenderung dikenakan pajak daripada capital gain, maka maka investor akan meminta tingkat keuntungan yang lebih tinggi untuk saham dengan dividend yield yang tinggi. Kelompok ini menyarankan bahwa dengan dividend payout ratio (DIVD) yang lebih rendah akan memaksimumkan nilai perusahaan. Ketiga pendapat nampak bertentangan, namun coba kita mempertimbangkan kandungan informasi, maka dapat dikatakan bahwa pembayaran dividen sering diikuti oleh kenaikan harga saham. 
Kenaikan pembayaran dividen dilihat sebagai signal bahwa perusahaan memiliki prospek yang baik. Sebaliknya penurunan pembayaran dividen akan dilihat sebagai prospek perusahaan yang buruk. Dengan demikian hipotesis yang dapat dibangun adalah:

H3: Kebijakan Dividen berpengaruh positif terhadap nilai perusahaan

\section{METODE PENELITIAN}

\section{Populasi dan Sampel}

Perusahaan yang menjadi populasi adalah seluruh perusahaan yang telah terdaftar di Bursa Efek Indonesia dan Bursa Efek Malaysia sejak tahun 2003 sampai dengan 2008. Sedangkan pemilihan sampel dengan menggunakan metode purposive sampling dengan tipe judgment sampling yaitu pemilihan sampel dengan mendasarkan pada kriteria tertentu (Cooper and Schindler, 2000). Memiliki laporan keuangan selama periode penelitian, tersedia data tentang persentase kepemilikan saham oleh direktur dan komisaris (insider ownership), membayar dividen, memiliki data jumlah hutang, memiliki EBIT yang positif dan memiliki Market Value Added yang positif atau Price Book Value lebih besar dari 1.

\section{Definisi Operasional \\ Insider ownership}

Adalah prosentase saham yang dimiliki oleh insider ownership (INSD), seperti manajer atau direktur, besarnya dapat dihitung sebagai berikut:

INSD $=\frac{\text { Jumlah saham yang dimiliki insider }}{\text { Total saham beredar }}$

\section{Kebijakan Hutang}

Hutang merupakan salah satu sumber pembiayaan eksternal yang digunakan oleh perusahaan untuk membiayai kebutuhan dananya. Dalam pengambilan keputusan akan penggunaan hutang ini harus mempertimbangkan besarnya biaya tetap yang muncul dari hutang berupa bunga yang akan menyebabkan semakin meningkatnya leverage keuangan dan semakin tidak pastinya tingkat pengembalian bagi para pemegang saham biasa. Tingkat penggunaan hutang dari suatu perusahaan dapat ditunjukkan oleh salah satunya menggunakan rasio hutang terhadap ekuitas (DER), yaitu rasio jumlah hutang terhadap jumlah modal sendiri.

DER $=\frac{\text { Total hutang atau kewajiban }}{\text { Total Modal Sendiri }}$

\section{Kebijakan deviden}

Kebijakan dividen adalah kebijakan yang dikaitkan dengan penentuan apakah laba yang diperoleh perusahaan akan dibagikan kepada para pemegang saham sebagai dividen atau akan ditahan dalam bentuk laba ditahan. Rasio keuangan yang dapat digunakan untuk menilai besarnya dividen yang dibagikan kepada pemegang saham dari laba bersih sesudah pajak (EAT) adalah Rasio Pembayaran Dividen. (DPR), yaitu rasio yang menunjukkan perbandingan antara Dividen Per lembar Saham (DPS) dengan Laba Per lembar Saham (LPS).

Marjin laba atas aset = Laba bersih sesudah pajak + bunga (1-T) Total Aktiva

DPR $=\frac{\text { Deviden per lembar saham }}{\text { Laba per lembar saham (LPS) }}$

\section{Nilai Perusahaan}

Price to book value atau PBV menggambarkan seberapa besar pasar menghargai nilai buku saham suatu perusahaan. Semakin tinggi rasio ini berarti pasar percaya akan prospek perusahaan tersebut.

$\mathrm{PBV}=\frac{\text { Harga saham }}{\mathrm{BV}}$ 
Nilai Buku (Book Value/BV) adalah rasio harga yang dihitung dengan membagi total aset bersih (Aset - Hutang) dengan total saham yang beredar.

$\mathrm{BV}($ book value $)=\frac{\text { Total Ekuitas }}{\text { Jumlah saham }}$

\section{Analisis Data}

Studi ini bertujuan untuk menganalisis faktor-faktor yang mempengaruhi nilai perusahaan pada perusahaan yang terdaftar di Bursa Efek Indonesia dan Bursa Efek Malaysia. Pengujian dilakukan dengan menggunakan Regresi Bertahap atau Multistage Regression. Adapun variabel yang diduga mempengaruhi Nila Perusahaan terdiri dari:

1. Insider ownership

2. Kebijakan hutang

3. Kebijakan dividen

Untuk mencari model terbaik atau fit, dilakukan dengan Regresi Bertahap dengan persamaan:

$\mathrm{Y} 1=\mathrm{bo}+\mathrm{b} 1 \cdot \mathrm{X} 1+\mathrm{b} 2 \cdot \mathrm{X} 2+\varepsilon$

$\mathrm{Y} 2=\mathrm{bo}+\mathrm{b} 3 . \mathrm{X} 3+\varepsilon$

HASIL ANALISIS DAN PEMBAHASAN Perusahaan yang Terdaftar di Bursa Efek Malaysia

\section{Uji Asumsi Klasik}

Untuk mencari model terbaik dilakukan regresi bertahap. Sebelum melakukan regresi berganda data diuji asumsi klasik. Berikut hasil uji asumsi klasik untuk datadata perusahaan yang terdaftar di Bursa Efek Malaysia:

\section{Uji Multikolinieritas}

Berdasarkan pada hasil output matriks korelasi, pair-wise korelasi antara kebijakan hutang dan insider ownership sebesar 0,332. Tidak terdapat multikolinearitas antar variabel dependen karena kurang dari 0,80 (Ghozali, 2009).

\section{Uji Heteroskedastisitas}

Dari scatterplot diperoleh bahwa titik-titik menyebar sehingga dapat disimpulkan bahwa tidak ada heteroskedastisitas (Ghozali, 2009).

\section{Uji Autokorelasi}

Nilai Durbin-Watson sebesar 2,348. Jika dibandingkan dengan nilai tabel $(\mathrm{n}=23)$ sebesar $\mathrm{dl}=1,168$ dan $\mathrm{du}=1,543$ maka nilai DW 2,348 lebih besar daripada batas atas (du) sehingga dapat disimpulkan bahwa tidak terdapat autokorelasi positif pada model regresi

\section{Uji Normalitas}

Besarnya nilai Kolmogorov-Smirnov adalah 1,041 dan tetapi tidak signifikan $(0,229)$ yang berarti residual terdistribusi decara normal (Ghozali, 2009). Dari hasil uji asumsi tersebut maka dapat disimpulkan bahwa data Bursa Efek Malaysia sudah memenuhi syarat asumsi untuk dapat dianalisis regresi.

\section{Uji Hipotesis 1 dan Hipotesis 2}

Pengaruh insider ownership dan kebijakan hutang terhadap nilai perusahaan pada perusahaan yang terdaftar di Bursa Malaysia dianalisis menggunakan regresi berganda.Hasil analisa regresi berganda dapat dilihat dalam tabel berikut ini. 
Tabel 1: Regresi Berganda Insider ownership dan Kebijakan Hutang terhadap Kebijakan Dividen pada Perusahaan yang Terdaftar di Bursa Malaysia

\begin{tabular}{cccccc}
\hline $\begin{array}{c}\text { Variabel } \\
\text { Independen }\end{array}$ & $\begin{array}{c}\text { Unstandardized } \\
\text { Coefficients } \\
\mathrm{B}\end{array}$ & $\begin{array}{c}\text { Standardized } \\
\text { Coefficients } \\
\text { Beta }\end{array}$ & Thitung & $\begin{array}{c}\text { Kolom } \\
\text { Sign }\end{array}$ & $\begin{array}{c}\text { Signifikansi } \\
(\alpha=10 \%)\end{array}$ \\
\hline $\begin{array}{c}\text { Constant }) \\
\begin{array}{c}\text { Insider } \\
\text { ownership }\end{array}\end{array}$ & -0.001 & & -0.133 & 0.895 & Signifikan \\
$\begin{array}{c}\text { Kebijakan } \\
\text { Hutang }\end{array}$ & 0.094 & 0.557 & 3.072 & 0.006 & Signifikan \\
\hline
\end{tabular}

Pengaruh insider ownership terhadap kebijakan dividen adalah positif dan signifikan $(\beta=0,094 ; \mathrm{t}=3,072 ;$ sign $=$ 0,006). Hubungan positif menunjukkan bahwa peningkatan insider ownership untuk meningkatkan persetujuan atau keselarasan (alignment) antara pemegang saham dengan manajer dalam meningkatkan keuntungan perusahaan akan memberi kesan secara signifikan terhadap peningkatan tingkat pembayaran dividen. Dalam konteks mekanisme pengawasan masalah agensi di dalam sebuah perusahaan, keadaan tersebut menunjukkan bahwa peningkatan insider ownership dapat menggantikan peranan kebijakan pembayaran dividen untuk mengurangi masalah agensi. Dengan kata lain, pembayaran dividen sebagai kebijakan keuangan dapat diganti peranannya oleh insider ownership sebagai kebijakan bukan keuangan dalam mekanisme pengawasan masalah agensi. Hasil kajian ini menolak hipotesis 1 dan tidak mendukung hasil kajian Jensen et al. (1992) yang menyatakan bahwa insider ownership berhubungan negatif dengan kebijakan dividen.

Pengaruh kebijakan hutang terhadap kebijakan dividen adalah negatif dan signifikan $(\beta=-0,002 ; \mathrm{t}=-1,032 ;$ sign $=$ -
0,007). Hubungan negatif ini menunjukkan terdapatnya hubungan antara kebijakan hutang dengan kebijakan pembayaran dividen. Hasil kajian ini mendukung hipotesis kedua yang dijelaskan pada persamaan kebijakan dividen. Hasil kajian mampu menerima hipotesis 2 dan mendukung kajian yang dilakukan oleh Jensen et al (1992) serta mampu menentang hasil penelitian Tandelilin dan Wilberforce (2002 dalam Harjito, 2007) yang menemukan hubungan positif dan signifikan antara pembayaran dividen dengan hutang.

Persamaan pengaruh insider ownership dan kebijakan hutang terhadap kebijakan dividen adalah: Divd $=-0,001+$ 0,094 Insd - 0,002 Debt

Dimana pengaruh insider ownership dan kebijakan hutang menyumbang 41,5\% untuk menjelaskan kebijakan dividen, sedangkan sisanya dipengaruhi variabel lain. (R Square $=0,415)$.

\section{Uji Hipotesis 3}

Untuk menganalisa pengaruh antara insider ownership dan kebijakan hutang melalui kebijakan dividen pada perusahaan yang terdaftar di Malaysia dihasilkan data sebagai berikut: 
Jurnal Siasat Bisnis Vol. 13 No. 2, Agustus 2009 Hal: 173-183

Tabel 2: Regresi Kebijakan Dividen terhadap Nilai Perusahaan pada Perusahaan yang Terdaftar di Bursa Malaysia

\begin{tabular}{cccccc}
\hline $\begin{array}{c}\text { Variabel } \\
\text { Independen }\end{array}$ & $\begin{array}{c}\text { Unstandardized } \\
\text { Coefficients } \\
\mathrm{B}\end{array}$ & $\begin{array}{c}\text { Standardized } \\
\text { Coefficients } \\
\text { Beta }\end{array}$ & $\begin{array}{c}\mathrm{T} \\
\text { hitung }\end{array}$ & $\begin{array}{c}\text { Kolom } \\
\text { Sign }\end{array}$ & $\begin{array}{c}\text { Signifikansi } \\
(\alpha=10 \%)\end{array}$ \\
\hline $\begin{array}{c}\text { Constant) } \\
\text { Kebijakan } \\
\text { Dividen }\end{array}$ & 1,416 & & 12,810 & 0,000 & Tidak \\
\hline
\end{tabular}

Variabel dividen (DIVD) mempunyai hubungan negatif namun tidak signifikan dengan nilai perusahaan $(\beta=-0,003 ; \mathrm{t}=-$ $0,013$, sign $=0,990)$. Hasil penelitian ini tidak dapat mendukung hipotesis 3 . Hipotesis 3 menyatakan bahwa kebijakan dividen berpengaruh positif terhadap nilai perusahaan. Oleh karena itu hipotesis 3 tidak terbukti dalam penelitian ini.

Hasil dari penelitian ini tidak mendukung bird in the hand theory (Gordon, 1962 dalam Brigham dan Gapensky, 1996) yang menyatakan bahwa dividen yang tinggi dapat meningkatkan nilai perusahaan karena pemegang saham lebih menyukai dividen yang tinggi karena memiliki kepastian yang tinggi dibandingkan capital gain. Hal ini menunjukkan bahwa pemegang saham tidak lagi melihat kebijakan dividen sebagai sinyal positif bahwa perusahaan dalam keadaan baik. Beberapa perusahaan berusaha tetap memberikan dividen walaupun dalam keadaan impas dan rugi agar dapat mempertahankan nilai perusahaannya. Praktek inilah yang disadari oleh pemegang saham sehingga kebijakan dividen tidak lagi dianggap sebagai faktor yang dapat mempengaruhi naiknya nilai perusahaan.

\section{Perusahaan yang Terdaftar di Bursa Efek Indonesia \\ Uji Asumsi Klasik}

Untuk mencari model terbaik dilakukan regresi bertahap. Sebelum melakukan regresi berganda data diuji asumsi klasik. Berikut hasil uji asumsi klasik untuk datadata perusahaan yang terdaftar di Bursa Efek Indonesia.

\section{Uji Multikolinieritas}

Berdasarkan pada hasil output matriks korelasi, pair-wise korelasi antara kebijakan hutang dan insider ownership sebesar 0,001 yang berarti tidak terdapat multikolinearitas antar variabel dependen karena kurang dari 0,80 (Ghozali, 2009).

\section{Uji Heteroskedastisitas}

Dari scatterplot diperoleh bahwa titik-titik menyebar sehingga dapat disimpulkan bahwa tidak ada heteroskedastisitas (Ghozali, 2009).

\section{Uji Autokorelasi}

Nilai Durbin-Watson sebesar 1,760. Jika dibandingkan dengan nilai tabel $(\mathrm{n}=23)$ sebesar $\mathrm{dl}=1,168$ dan $\mathrm{du}=1,543$ maka nilai DW 1,760 lebih besar daripada batas atas (du) sehingga dapat disimpulkan bahwa tidak terdapat autokorelasi positif pada model regresi (Ghozali, 2009).

\section{Uji Normalitas}

Besarnya nilai Kolmogorov-Smirnov adalah 0,945 dan tetapi tidak signifikan $(0,334)$ yang berarti residual terdistribusi decara normal (Ghozali, 2009). Dari hasil uji asumsi tersebut maka dapat disimpulkan bahwa data Bursa Efek Indonesia sudah memenuhi syarat asumsi untuk dapat dianalisis regresi.

\section{Uji Hipotesis 1 dan Hipotesis 2}

Pengaruh insider ownership dan kebijakan hutang terhadap nilai perusahaan pada perusahaan yag terdaftar di Bursa Efek 
Indonesia dianalisis menggunakan regresi berganda. Hasil analisa regresi berganda dapat dilihat dalam tabel 3. Pengaruh insider ownership terhadap kebijakan dividen adalah positif namun tidak signifikan $(\beta=$ $0,044 ; \mathrm{t}=0,327$; sign $=0,745)$. Hubungan positif ini menunjukkan bahwa peningkatan insider ownership untuk meningkatkan persetujuan atau keselarasan (alignment) antara pemegang saham dengan manajer dalam meningkatkan keuntungan perusahaan akan tidak memberi kesan secara signifikan terhadap peningkatan tingkat pembayaran dividen. Hasil kajian ini menolak hipotesis 1 serta tidak mendukung hasil kajian Jensen et al. (1992) yang menyatakan bahwa insider ownership berhubungan negatif dengan kebijakan dividen. Walau bagaimanapun, hasil kajian ini mendukung hasil kajian Tandelilin dan Wilberforce 2002 dan Miguel et al. 2005 (Harjito, 2007). Kedua kajian ini menemukan tidak terdapat hubungan antara insider ownership dan tingkat pembayaran dividen.
Pengaruh kebijakan hutang terhadap kebijakan dividen adalah negatif dan signifikan $(\beta=-0,151 ; \mathrm{t}=-1,115 ; \operatorname{sign}=$ $0,270)$. Hubungan negatif ini menunjukkan terdapatnya hubungan antara kebijakan hutang dengan kebijakan pembayaran dividen. Hasil kajian ini tidak mampu mendukung hipotesis kedua yang dijelaskan pada persamaan kebijakan dividen. Hasil kajian ini menolak hipotesis 2 dan tidak mendukung kajian yang dilakukan oleh Jensen et al (1992) serta mampu menentang hasil penelitian Tendelilin dan Wilberforce (2002 dalam Harjito, 2007)) yang menemukan hubungan positif dan signifikan antara pembayaran dividen dengan hutang.

Persamaan pengaruh insider ownership dan kebijakan hutang terhadap kebijakan dividen adalah: Divd $=0,054+$ 0,003 Insd - 0,005 Debt

Dimana pengaruh insider ownership dan kebijakan hutang menyumbang 2,5\% untuk menjelaskan kebijakan dividen, sedangkan sisanya dipengaruhi variabel lain. $(\mathrm{R}$ Square $=0,025)$.

Tabel 3: Regresi Berganda Insider ownership dan Kebijakan Hutang terhadap Kebijakan Dividen pada Perusahaan yang Terdaftar di Bursa Efek Indonesia

\begin{tabular}{cccccc}
\hline $\begin{array}{c}\text { Variabel } \\
\text { Independen }\end{array}$ & $\begin{array}{c}\text { Unstandardized } \\
\text { Coefficients B }\end{array}$ & $\begin{array}{c}\text { Standardized } \\
\text { Coefficients B }\end{array}$ & T hitung & $\begin{array}{c}\text { Kolom } \\
\text { Sign }\end{array}$ & $\begin{array}{c}\text { Signifikansi } \\
(\alpha=10 \%)\end{array}$ \\
\hline (Constant) & 0,054 & & 2,280 & 0,270 & Tidak \\
Insider ownership & 0,003 & 0,044 & 0,327 & 0,745 & $\begin{array}{c}\text { Signifikan } \\
\text { Tidak }\end{array}$ \\
Kebijakan Hutang & $-0,005$ & $-0,151$ & $-1,115$ & 0,270 & Signifikan \\
\hline
\end{tabular}

\section{Uji Hipotesis 3}

Tabel 4: Regresi Kebijakan Dividen terhadap Nilai Perusahaan pada Perusahaan yang Terdaftar di Bursa Efek Indonesia

\begin{tabular}{|c|c|c|c|c|c|}
\hline $\begin{array}{c}\text { Variabel } \\
\text { Independen }\end{array}$ & $\begin{array}{c}\text { Unstandardized } \\
\text { Coefficients } \\
\text { B }\end{array}$ & $\begin{array}{c}\text { Standardized } \\
\text { Coefficients } \\
\text { Beta }\end{array}$ & $\begin{array}{c}\mathrm{T} \\
\text { hitung }\end{array}$ & $\begin{array}{c}\text { Kolom } \\
\text { Sign }\end{array}$ & $\begin{array}{c}\text { Signifikans } \\
(\alpha=10 \%)\end{array}$ \\
\hline (Constant) & 1,278 & & 5,886 & 0,000 & \\
\hline $\begin{array}{c}\text { Kebijakan } \\
\text { Dividen }\end{array}$ & $-1,146$ & $-0,189$ & $-0,884$ & 0,387 & $\begin{array}{c}\text { Tidak } \\
\text { Signifikan }\end{array}$ \\
\hline
\end{tabular}


Untuk menganalisa pengaruh antara insider ownership dan kebijakan hutang melalui kebijakan dividen pada perusahaan yang terdaftar di Bursa Efek Indonesia dihasilkan data sebagaimana tampak pada Tabel 4.

Variabel dividen (DIVD) mempunyai hubungan negatif dan tidak signifikan dengan nilai perusahaan $(\beta=-1,146 ; \mathrm{t}=$ $0,387$, sign $=0,387)$. Hasil penelitian ini tidak dapat mendukung hipotesis 3 . Hipotesis 3 menyatakan bahwa kebijakan dividen berpengaruh positif terhadap nilai perusahaan. Oleh karena itu hipotesis 3 tidak terbukti dalam penelitian ini.

Hasil dari penelitian ini tidak mendukung bird in the hand theory (Gordon, 1962 dalam Brigham dan Gapensky, 1996) yang menyatakan bahwa dividen yang tinggi dapat meningkatkan nilai perusahaan karena pemegang saham lebih menyukai dividen yang tinggi karena memiliki kepastian yang tinggi dibandingkan capital gain. Hal ini menunjukkan bahwa pemegang saham tidak lagi melihat kebijakan dividen sebagai sinyal positif bahwa perusahaan dalam keadaan baik. Beberapa perusahaan berusaha tetap memberikan dividen walaupun dalam keadaan impas dan rugi agar dapat mempertahankan nilai perusahaannya. Praktek inilah yang disadari oleh pemegang saham sehingga kebijakan dividen tidak lagi dianggap sebagai faktor yang dapat mempengaruhi naiknya nilai perusahaan.

\section{PENUTUP}

Dari hasil analisis di atas dapat disimpulkan bahwa perusahaan yang terdaftar di Bursa Malaysia kebijakan dividen dipengaruhi oleh insider ownership dan kebijakan hutang, sedangkan di Indonesia tidak. Hal ini mengindikasikan bahwa undang-undang yang terapkan di Malaysia berkaitan dengan perlindungan hukum investor dirasa lebih efektif untuk mengendalian manajer dan insider ownership, sehingga insider tidak mungkin meningkatkan nilai perusahaan karena kepentingan antara pemilik dan agen diselaraskan karena kontrol pasar dan tindakan disiplin manajer.

Selain itu nilai perusahaan yang terdaftar di Bursa Malaysia dan Bursa Efek Indonesia tidak dipengaruhi oleh kebijakan dividen. Hal ini tidak sesuai dengan bird hand theory (Gordon, 1962 dalam Brigham dan Gapensky, 1996) yang menyatakan bahwa dividen yang tinggi dapat meningkatkan nilai perusahaan karena pemegang saham lebih menyukai dividen yang tinggi karena memiliki kepastian yang tinggi dibandingkan capital gain. Hal ini menunjukkan bahwa pemegang saham tidak lagi melihat kebijakan dividen sebagai sinyal positif bahwa perusahaan dalam keadaan baik. Beberapa perusahaan berusaha tetap memberikan dividen walaupun dalam keadaan impas dan rugi agar dapat mempertahankan nilai perusahaannya. Praktek inilah yang disadari oleh pemegang saham sehingga kebijakan dividen tidak lagi dianggap sebagai faktor yang dapat mempengaruhi naiknya nilai perusahaan.

Dari kesimpulan di atas, kami menyarankan agar peraturan hukum penanaman modal dan undang-undang perseroan terbatas perlu dikaji ulang agar terjadi fairness antara manajer dan pemilik modal sehingga tidak ada lagi asymmetry information dan insider trading yang sangat merugikan investor.

\section{DAFTAR PUSTAKA}

Brigham, E.F. and Houston, J.F. (1996). Manajemen Keuangan. Edisi Bahasa Indonesia. Jakarta: Erlangga.

Brigham, E.F. and Gapenski, L.C. (1990). Intermediate Financial Management. Florida: The Dryden Press.

Coopers, D.R., and Schindler, P.S. (2000). Business Research Methods. New 
York: McGraw-Hill International editions.

Easterbrook, F.H. (1984). Two Agency-Cost Explanation Of Dividends. American Economic Review, 74 (4), 650-659.

Ghozali, I. (2009). Ekonometrika: Teori, Konsep, dan Aplikasi dengan SPSS 17. Semarang: Badan Penerbit Universitas Diponegoro.

Gordon, M.J., (1959). Dividends, Earnings, and Stock Prices. The Review of Economics and Statistics, 41(2), 99-105.

Harjito, D. A. (2006). Hubungan Kebijakan Hutang, Insider ownership dan Kebijakan Dividen dalam Mekanisme Pengawasan Masalah Agensi di Indonesia. Jurnal Akuntansi dan Auditing Indonesia, 10 (2), 161-182.

Harjito, D. A., (2007). Analisis Hubungan antara Kepemilikan Insider, Leverage Perusahaan dan Kebijakan Dividen. Telaah Bisnis, 8 (1), 45-60.

Hartono, J,. (2005). Teori Portofolio dan Analisis Investasi. Yogyakarta: BPFE UGM

Jensen, M.C. (1986). Agency Costs Of Free Cash Flow, Corporate Finance, And Takeovers. American Economic Review, 76 (2), 323-329.

Jensen, M., C. and Meckling, W.H. (1976). Theory of the Firm: Managerial Behavior, Agency Cost, and Ownership Structure. Journal of Financial Economics, 3-24.
Jensen, M., C. and Meckling, W.H. (1976). Theory of the firm: Managerial behavior, agency, and ownership structure. Journal of Financial Economics, 4, 305-360.

Jensen, Solberg, and Zorn. (1992). Simultaneous determination of insider ownership, debt, and dividend policies. Journal of Financial and Quantitative Analysis, 27 (2), 247-263.

La Porta. (1998). Law and Finance. Journal of Political Economy, 106, 11131155.

(2002). Investor Protection and Corporate Valuation. Journal of Finance, 57, 1147 - 1170.

Leland, H. and Pyle, D. (1977). Informational asymetries, financial structure, and financial intermediation. Journal of Finance, $32,371-388$.

Lisboa, I and Esperanca, J.P. (2006). Understanding the Relationship Between Insider ownership and Performance in Europe.

Masulis, R., W. (1988). Debt/Equity Choice. Canbridge: Ballinger.

Ross, S. (1977). The Determinations of Financial Structure: The Incentive Signaling Approach. Bell Journal of Economics, 8, 23-40.

Soliha, E. dan Taswan. (2002). Pengaruh Kebijakan Hutang terhadap Nilai Perusahan serta Beberapa Faktor yang Mempengaruhinya. Jurnal Bisnis dan Ekonomi. 